\title{
Information system for environmental monitoring of liquidated mining enterprises
}

\author{
Alexander Abramovich ${ }^{1 *}$, and Dinara Dzhekibaeva ${ }^{2}$ \\ ${ }^{1}$ Branch of T.F. Gorbachev Kuzbass State Technical University in Prokopievsk, 653039, 19a \\ Nogradskaya str., Prokopievsk, Kemerovo region, Russian Federation \\ ${ }^{2}$ Ekibastuz Engineering and Technical Institute named after Academician K. Satpayev, 141208, 54A \\ Energetikov str., Ekibastuz, Republic of Kazakhstan
}

\begin{abstract}
The article presents the concept and the development of an information system for environmental monitoring of land parcels, that have already been robbed-out, and land parcels, that are still being mined by open cut mining, through the example of research carried out on the territory of the Kemerovo region - Kuzbass. The paper presents the concept of an information system: the data collection principle with the use of unmanned aerial vehicles, and presents the full attribute relational database model, which is a data warehouse. A list of subsystems of the information system is also presented, as well as the principle of carrying out of environmental monitoring of fires that occur on culm banks during open cut mining, and the facilities of the information system.
\end{abstract}

\section{Introduction}

At the present time there is a rapid increase in the mineral output. The mass of extractable resources is produced during open cut mining. Currently, in the territory of the Kemerovo Region - Kuzbass, there are many land parcels, on which open cut mining was previously carried out for the extraction of minerals. Many of them have already been robbed-out and mining operations are not performed on them, however, they still continue to be not reclaimed and there are thermodynamic processes on many culm banks. In certain instances thermodynamic processes can take place for tens of years before a fire breaks out, which may lead to downfalls, gas formations and outbursts, which raises the pressing question of continuous and periodic monitoring of land parcels, that have already been robbed-out, and land parcels, that are still being mined by open cut mining [1-9].

These days there is a rapid evolution of various areas of information technology and their further application in almost all spheres of human life. The automation of information processes is the most pressing area in the tech field. At the moment, there are a great number of different information systems and software deal with industrial, social and business needs, which are supplied by a large number of development organizations. A variety of hardware-software solutions of Russian and foreign developers have been implemented for the computerization of set of tasks in different areas [10-11]. In spite of

*Corresponding author: abramovichas@,kuzstu.ru 
that, software and computing are not used to perform and solve a variety of processes and tasks. One of such processes is the process of environmental monitoring of land parcels that are located in the districts of open cut mining, which confirms the relevance of the research.

\section{Formulation of the problem}

The issues of environmental monitoring of land parcels located in the districts of open cut mining can include many criteria by which it is necessary to carry out surveys and analysis of such land parcels, these include:

1. monitoring of auto roads;

2. monitoring of pit walls in open cut mining;

3. monitoring of forestall areas for the outbreak of fires;

4. monitoring of fires occurring at culm banks.

Currently, there are no information systems for environmental monitoring of land parcels that are environmentally disturbed by open cut mining, and data collection in which is conducted with the application of unmanned aerial vehicles (UAVs) [12]. It is suggested to develop a unified information system for monitoring the ecological state of land parcels located in the districts of open cut mining. This system will consist of multiple subsystems:

1. a subsystem for monitoring auto roads;

2. a subsystem for monitoring of pit walls in open cut mining;

3. a subsystem for monitoring forestall areas for the outbreak of fires;

4. a subsystem for monitoring of fires occurring at culm banks.

The offered information system is a large project and requires a lot of investment for its development.

Due to the lack of scientific studies in the area of monitoring fires occurring at culm banks, it was decided to start the development of an information system with a subsystem for monitoring fires occurring at culm banks in the districts of land parcels where open cut mining for the extraction of minerals is being carried out or was previously carried out. The information system data will be stored in a database, which is implemented on the cloud.

The essential requirements for the development of an information system are the versatility and scalability of the system, since environmental monitoring is carried out holistically, and for a complete assessment of the ecological state of land parcels located within and outside of mine takes, a large number of different unconnected parameters are required.

\section{Research result}

The principle of environmental monitoring of culm banks fires involves collecting data by using UAV, which maintains the survey access via use of infrared thermography and the application of mix of methods, including georadiolocation, which are well-proven for such research [13-15]. The findings are saved in the database for further analysis using special software. At the current time, the first studies with the use of method of infrared thermography have been carried out at mine takes of liquidated enterprises in the Kemerovo region. The investigation of land parcels was carried out with the use of UAV. Many photographs, including infrared, were taken in the course of the research. The photograph of the land parcel under study is shown in Fig.1. 


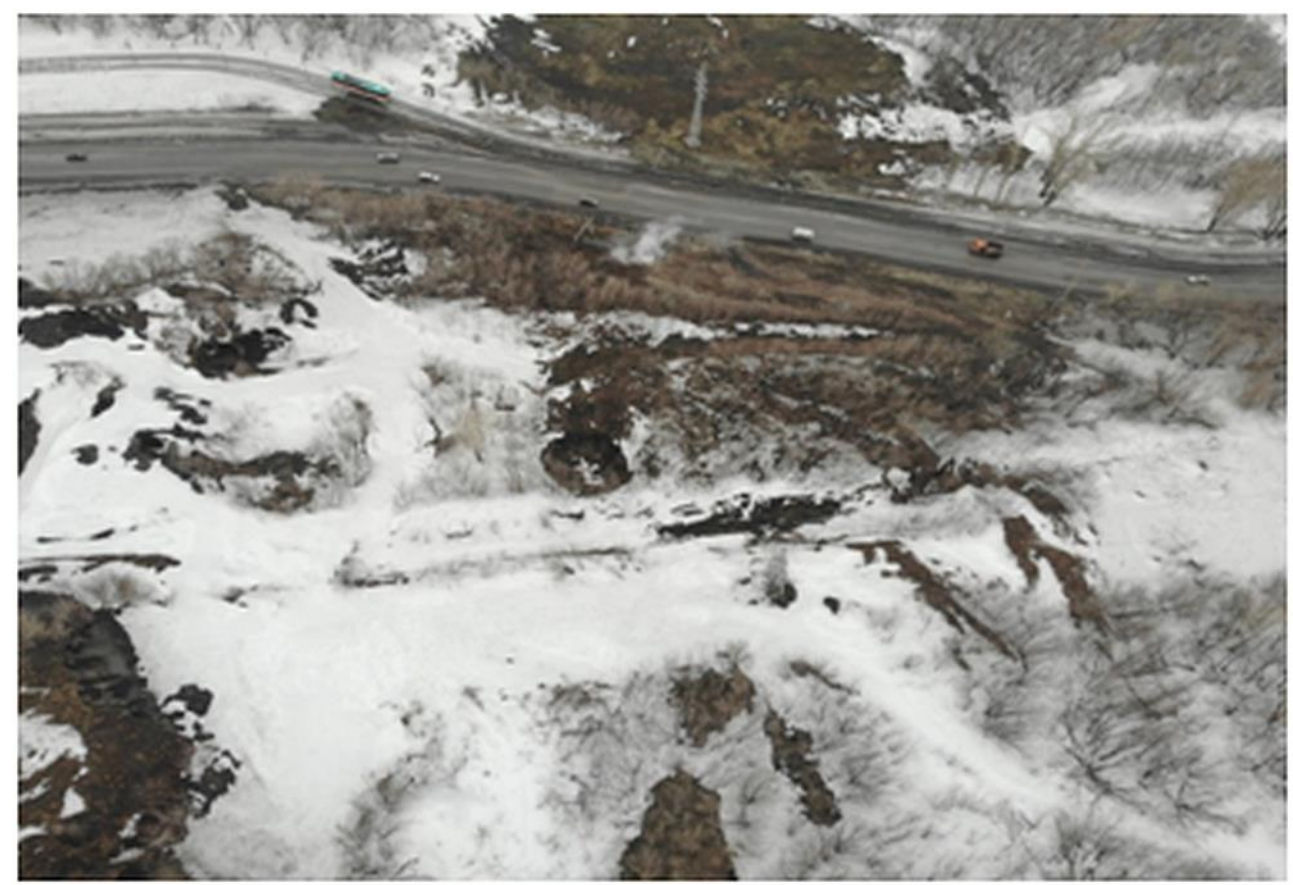

Fig. 1. Survey of the land parcel under study via UAV

The thermogram of the land parcel under study, survey via UAV, is shown in Fig.2.

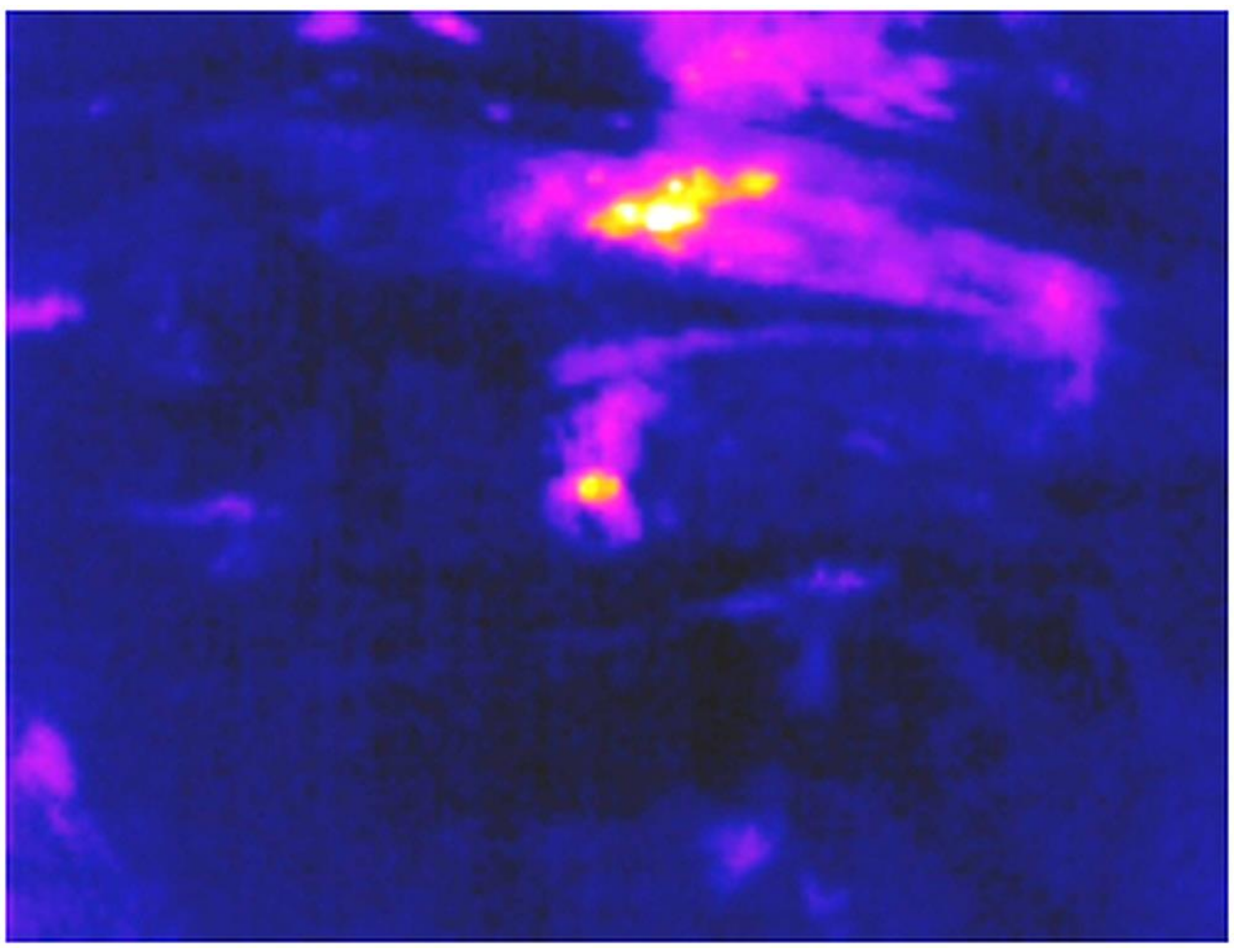

Fig. 2. Survey of the land parcel under study via UAV. The thermogram 
After adding the data obtained from the UAV to the database, the data diagram of which is shown in Figures 3-4, it is planned in this subsystem to visualize the received data on an electronic map with an option to form layers on the map according to the data of land parcels under study and with an option of further chronological data analysis. Geographic information system QGIS will be used to visualize the data on the map.

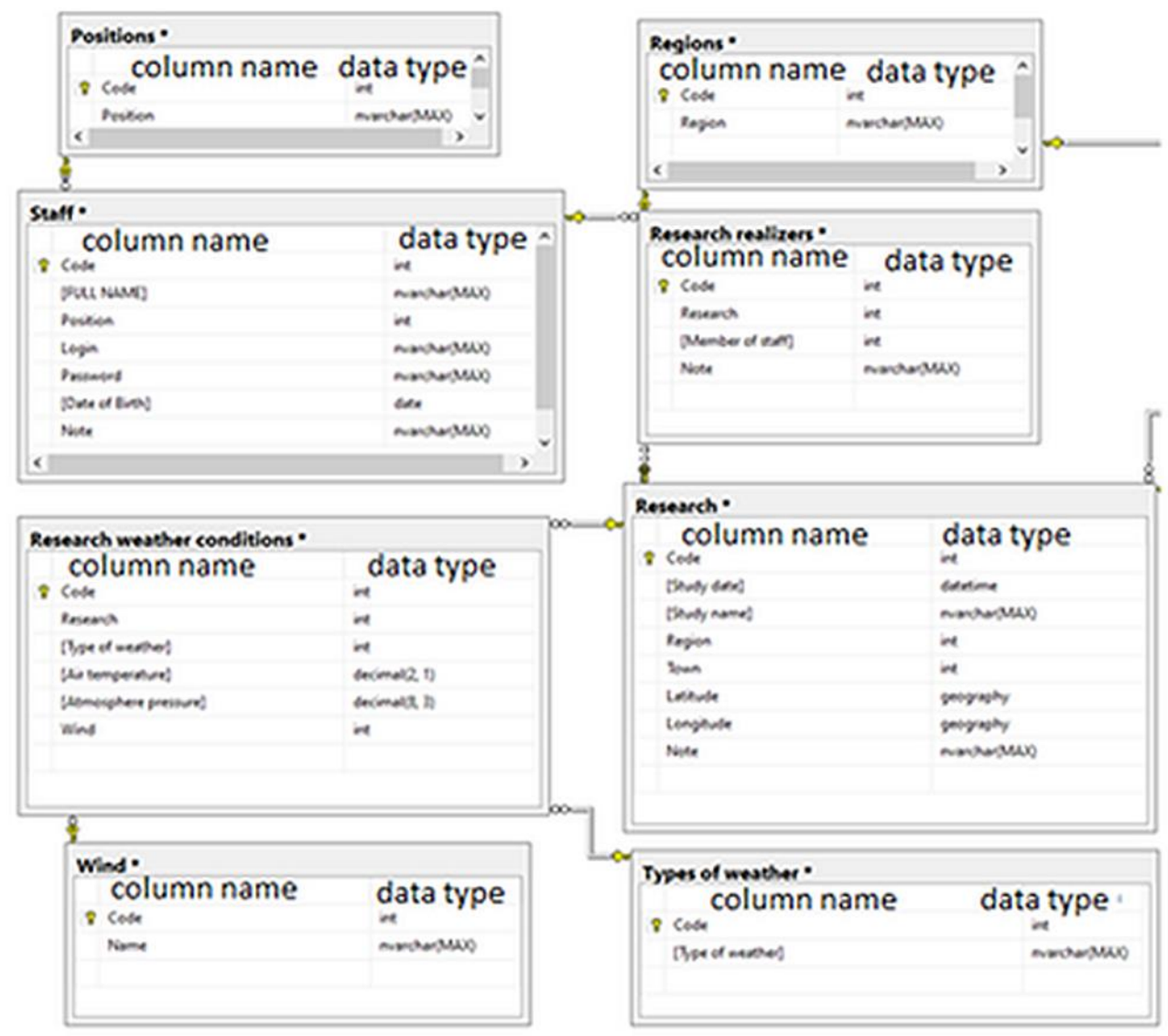

Fig. 3. Data diagram of the database of environmental monitoring of land parcels (research of thermodynamic processes). Left side. 


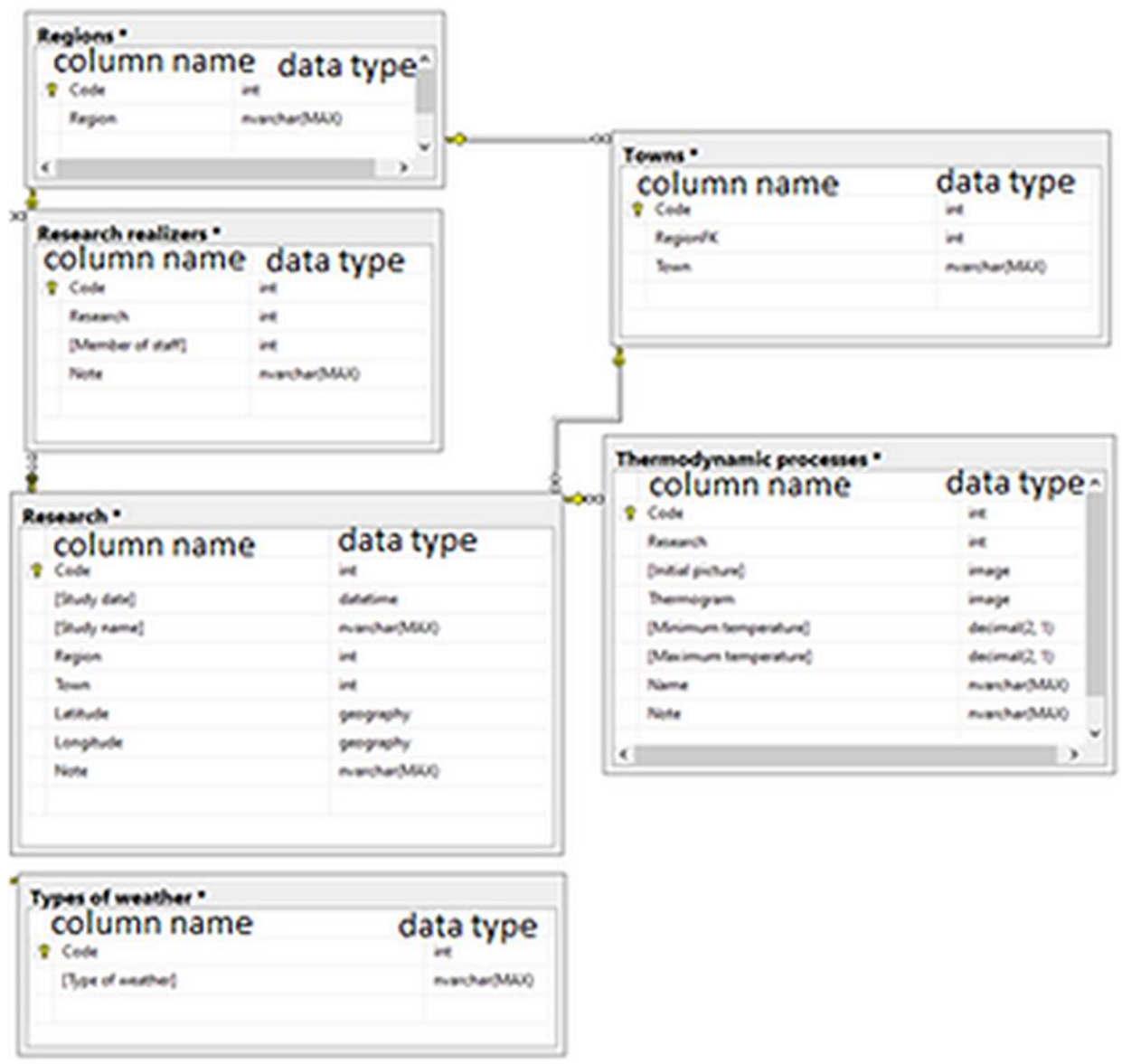

Fig. 4. Data diagram of the database of environmental monitoring of land parcels (research of thermodynamic processes). Right side

\section{Conclusion}

Application of the proposed information system will allow:

1. to carry out an analysis of ecological state of land parcels that are located in the districts of open cut mining, both in-depth and analysis by individual parameters;

2. to develop heat maps of thermodynamic disturbances that occur on culm banks during open cut mining, on which dumping is still taking place and on which work has already been stopped;

3. to improve the safety of life in the vicinity of the liquidated mining works.

\section{References}

1. A. Abramovich, Yu. Stepanov, J. of E3S Web of Conferences, 134, 01001 (2019)

2. A. Abramovich, Yu. Stepanov, J. of E3S Web of Conferences, 174, 01051 (2020)

3. M. Larson, D. Tesarik, J.Seymour, R. Rains, Inf. Circ. 151, 253 (2000)

4. Z. Zhang, J. Bai, Y. Chen, S. Yan, Int. J. Rock Mech. Min. Sci., 80, 1 (2015)

5. Y. Lu, W. Yang, J. of Central South. Univer. 20, 1397 (2013) 
6. A. Chanyshev, I. Abdulin, J. of Mining Sci. 50, 18 (2014)

7. V. Vaziri, J. Hamidi, A. Sayadi, Environ. Earth Sci. 77, 1 (2018)

8. S. Kostyuk, A. Gegreen, V. Meljnik, M. Lupeey, E3S Web Conf., 21, 01035 (2017)

9. A. Catalano, F.A. Bruno, M. Pisco, A. Cutolo, A. Cusano, Sensors. 14, 18268 (2014)

10. M. Satya, O. Anurag, M. Sachin, Nat. Conf. OSGIS-2015, 150 (2015)

11. J. Doherty, A. Hasan, G. Suazo, A. Fury. Can. Geotech. J. 52, 1901 (2015)

12. M. Koryagin, O. Marinova, E. Izhmulkina, VIVUS-14 (2014)

13. V.I. Klishin, B.L. Gerike, E.G. Kuzin, et. al. MIAB S38, 369 (2017)

14. S.O. Markov, M.A. Tyulenev, E.A. Kuzin. Mining engineering and technology. 1, 56 (2018)

15. E. Kuzin, V. Shahmanov, D. Dubinkin. E3S Web of Conferences. 21, 03006 (2017) 